\title{
Avaliação da padronização das mídias sociais gerenciadas pelo Ministério do Turismo
}

Social media standardization assessment managed by the Ministry of Tourism

Kathleen K. Brandt Silveira (kathleenbs@hotmail.com)

Universidade do Vale do Itajaí, Brasil

Lucimari Acosta Pereira (lucimari.svp@gmail.com)

Universidade do Vale do Itajaí, Brasil

Pablo Flôres Limberger (pablofl@univali.br)

Universidade do Vale do Itajaí, Brasil

\section{RESUMO}

Ao considerar a rápida expansão de serviços de informação, principalmente no ambiente online, tem-se para o setor turístico a potencial ferramenta que são as mídias sociais, que exercem o papel fundamental de socialização de ideias, estimulando e disseminando informações. Deste modo, torna-se considerável a atuação do poder público e organização das políticas públicas com a intenção de disseminar a comunicação pública para promover articulação entre os diversos atores sociais envolvidos nos seus planos, programas e projetos, via ambiente online. O presente estudo teve como objetivo avaliar a padronização das mídias sociais gerenciadas pelo Ministério do Turismo. Para isso, realizou-se uma pesquisa bibliográfica, de caráter qualitativo, utilizando fontes secundárias para uma análise documental e avaliativa por meio da verificação do Manual de Orientações para Atuação em Mídias Sociais (Identidade padrão de comunicação digital do poder executivo federal), disponibilizado pela Secretaria de Comunicação Social Brasileira. Foram avaliadas as mídias sociais utilizadas pelo Ministério do Turismo, sendo estas: Facebook, Twitter, YouTube, Google + , Instagram, Pinterest e Flickr. A análise foi realizada considerando o ano de 2017 e o ano de 2020. Os resultados deste estudo apontaram que as atuais mídias sociais utilizadas pelo Ministério do Turismo estão estrategicamente sendo utilizadas, mas não seguem uma padronização visual adequada. Os conteúdos publicados conseguem transmitir, a partir da padronização, uma mensagem direta e clara dentro do contexto da comunicação nas mídias 
sociais e condizem com a proposta do setor. Além de apresentar os destinos, eventos, regulamentações e fatos importantes do setor.

Palavras-Chave: Mídias Sociais; Políticas Públicas; Ministério do Turismo

\section{ABSTRACT}

When considering the rapid expansion of information services, especially in the online environment, there is a potential tool for the tourism sector, which are social media. Social media play a fundamental role of socializing ideas, stimulating and disseminating information. In this way, the role of public authorities and the organization of public policies is considerable, with the intention of disseminating public communication to promote articulation between the various social actors involved in their plans, programs and projects, via the online environment. This study aim at to assess the standardization of social media managed by the Ministry of Tourism. For this, a bibliographic research, with a qualitative approach, was carried out. The research used secondary sources for a documentary and evaluative analysis through the verification of the Manual of Guidelines for Performance in Social Media (Standard identity of digital communication of the federal executive power), made available by Brazilian Social Communication Secretariat. The social media used by the Ministry of Tourism were evaluated, namely: Facebook, Twitter, YouTube, Google +, Instagram, Pinterest and Flickr. The analysis was carried out considering the year 2017 and the year 2020. The results of this study pointed out that the current social media used by the Ministry of Tourism are being strategically used, but do not follow an adequate visual standardization. Published content is capable of transmitting, based on standardization, a direct and clear message within the context of communication on social media and are consistent with the sector's proposal. In addition to presenting the destinations, events, regulations and important facts of the sector.

Keywords: Social Media; Public Policy; Ministry of Tourism.

\section{INTRODUÇÃO}

Os avanços das tecnologias da informação e comunicação (TICs) geraram grandes transformações no setor de turismo, afetando clientes e fornecedores. As TICS, e especialmente a Web, passaram a oferecer novas oportunidades e recursos para melhorar as organizações e destinos turísticos, assim como aumentar a competitividade, lucratividade e reputação de marcas nos diversos setores de serviço deste ramo econômico (Minazzi, 2015; Moro, Rita \& Vala, 2016; Arman \& Sidik, 2019). 
Dentro desse cenário de avanço tecnológico constante, nos últimos anos, a distribuição de produtos turísticos e destinos de viagens tem sofrido profundas alterações, fruto da evolução dos meios de comunicação (Kiralova \& Pavliceka, 2015). Cabe salientar, adicionalmente, que as mídias sociais assumiram um papel importante enquanto fonte de informação estratégica no turismo, o que pode ter impacto no seu desenvolvimento e competitividade (Thomaz et al., 2016).

Esta distribuição de conteúdo por meio de mídias sociais proporciona uma intensa troca de informações onde os usuários são capazes de acessar facilmente grande quantidade de dados relevantes para sua necessidade (Souza \& Machado, 2017). No turismo, esta dinâmica se concentra em buscar informações de destinos e conteúdos relevantes que possam auxiliar positivamente na tomada de decisão do turista (Kiralova \& Pavliceka, 2015).

Por esta dinâmica de distribuição e busca de informação online, tornase considerável a atuação do poder público na organização de políticas que objetivem disseminar a comunicação pública para promover articulação entre os diversos atores sociais envolvidos nos seus planos, programas e projetos. Nesse sentido, o presente trabalho teve como objetivo avaliar a padronização das mídias sociais gerenciadas pelo Ministério do Turismo. Os resultados apontaram, de uma forma geral, que as mídias sociais não têm seguido uma padronização adequada. Em se tratando de contribuição, a pesquisa apresenta uma contribuição acadêmica e gerencial. Quanto a estrutura, este estudo organiza-se em cinco partes, que compreende: Introdução, referencial teórico, procedimentos metodológicos, análise de dados e considerações finais.

\section{POLÍTICAS PÚBLICAS DE TURISMO NO BRASIL}


Políticas públicas são um conjunto de ações com a finalidade de estabelecer o controle ou autoridade social sobre bens, serviços, e obras públicas. Neste sentido, são realizadas intervenções pelo poder público, instituições civis, entidades privadas ou grupos comunitários, que devem atender a população e suas necessidades materiais e simbólicas, construindo normas jurídicas com intervenções diretas, amplas e pontuais (Gastal \& Moesch, 2007).

Na concepção de Sheppard e Fennell (2019) a política de turismo é um dos influenciadores da articulação e modelagem do setor. Ou seja, é o que irá nortear os impactos socioculturais, econômicos e sustentáveis, auxiliando, por exemplo, nos benefícios de uma comunidade.

Para alcançar desenvolvimento, principalmente no setor do turismo, o Brasil tem criado políticas que articulam desde a descentralização até a regulamentação de ações, de órgãos governamentais. Essas políticas são fundamentais para o sucesso desta área, pois tem como uma de suas principais funções estabelecer regras e diretrizes "a serem cumpridas a longo e médio prazo; sem estas diretrizes o setor está destinado ao insucesso." (Silva, Costa \& Carvalho, 2013, p. 4).

Neste âmbito evidencia-se então que "as políticas públicas podem ser consideradas a solução para a superação de muitos dos problemas, barreiras e impactos que limitam a difusão do lazer e do turismo na sociedade atual" (Clemente \& Stoppa, 2018, p. 357).

No setor do turismo as políticas públicas necessitam ter normatização jurídica, realizar intervenções diretas que precisam ser realizadas por meio de linhas de financiamentos, implantação de infraestrutura, gerenciamento de informações, treinamento e qualificação de recursos humanos, além de consolidar diretrizes que não só incentivem o turismo no sentido econômico mas também nas suas implicações socioculturais centradas tanto no turista quanto nos residentes de um destino (Gastal \& Moesch, 2007).

Beni (2006, p. 103) evidencia que: 
Deve-se entender por política de Turismo o conjunto de fatores condicionantes e de diretrizes básicas que expressam os caminhos para atingir os objetivos globais para o Turismo do país; determinam as prioridades da ação executiva, supletiva ou assistencial do Estado; facilitam o planeamento de empresas do setor quanto aos empreendimentos e as atividades mais suscetíveis de receber apoio estatal. Ela deverá nortear-se por três grandes condicionamentos- $O$ cultural, o social e o econômico- por mais simples ou ambiciosos que seja, os programas, os projetos e as atividades a desenvolver; por menores ou maiores que sejam as áreas geográficas em que devam ocorrer; quaisquer que sejam suas motivações principais ou os setores econômicos aos quais possam interessar (BENI, 2006, p. 103).

Vignati (2008), nessa perspectiva, aponta que o turismo precisa de políticas próprias, que visem o crescimento em bases competitivas e sustentáveis, tendo em vista tanto que este setor possui complexidade no seu sistema econômico, quanto a diversidade dos agentes que influenciam no desenvolvimento e qualidade de um destino turístico.

No Brasil algumas políticas de turismo datadas a partir de 1996, trazem mudanças importantes ao setor, e caracterizam-se pela maturação do governo e empresariado no que tange a gestão de destinos. Alguns exemplos podem ser vistos no quadro (1)a seguir:

Quadro 1: Evolução das políticas de Turismo

\begin{tabular}{|l|l|}
\hline Política Nacional de Turismo & $1996-1197$ \\
\hline Programa Nacional de Municipalização do Turismo & $2001-2003$ \\
\hline Ministério do Esporte e Turismo & 2003 \\
\hline Ministério do Turismo & 2003 \\
\hline Plano Nacional de Turismo & $2003-2007$ \\
\hline Programa de Regionalização do Turismo & 2004 \\
\hline Plano de Marketing Turístico Internacional & 2005 \\
\hline Plano de Marketing Turístico dirigido para o Mercado Doméstico & 2005 \\
\hline
\end{tabular}

Fonte: Vignati, (2008). Adaptado pelos autores.

De acordo com Vignati (2008, p. 77), "a política de turismo vem ganhando importância à medida que se atribui ao turismo a capacidade de catalisar processos de geração de trabalho, renda e desenvolvimento 
socioeconômico". Neste sentido o autor aponta que planos de marketing são instrumentos básicos de política para o turismo, pois são documentos que abarcam um conjunto de ações essenciais para promover o desenvolvimento e a comercialização de um destino turístico, sendo este resultado final de um processo formalizado de planejamentos e negociações, definindo objetivos e identificando ações para poder alcançá-los (VIGNATI, 2008).

Para Beni (2006) as políticas públicas servem como ferramentas capazes de nortear o desenvolvimento do setor turístico e são capazes de guiar as ações realizadas, dando direção aos gestores. $\bigcirc$ autor, desse modo, traz alguns princípios que devem estar presentes na formulação de políticas públicas para o turismo e que se encontram no quadro (2):

Quadro2: Princípios para Formulação de Políticas Públicas para o Turismo

\begin{tabular}{|l|l|l|}
\hline 1. Satisfação do visitante & $\begin{array}{l}\text { O turismo deve ser originado do deslocamento voluntário, } \\
\text { neste sentido deve ter a capacidade de satisfação do } \\
\text { cliente para que possa pôr em prática assim o } \\
\text { funcionamento do Sistur. }\end{array}$ \\
\hline 2. $\quad \begin{array}{l}\text { Proteção ao meio } \\
\text { ambiente natural }\end{array}$ & $\begin{array}{l}\text { Quanto maior forem os benefícios de um Estado com a } \\
\text { atividade turística, maior deve ser a responsabilidade do } \\
\text { mesmo com o meio ambiente natural, neste sentido a } \\
\text { administração pública deve ter responsabilidade e } \\
\text { compromisso de preservar. }\end{array}$ \\
\hline 3. & $\begin{array}{l}\text { Benefício justo para os os que ocorra o desenvolvimento turístico é necessário } \\
\text { investidores } \\
\text { canalizar recursos do setor privado, para evitar que se } \\
\text { recorra ao uso de públicos, neste sentido faz-se necessário } \\
\text { políticas de benefícios justos aos investidores. }\end{array}$ \\
\hline
\end{tabular}

Fonte: Beni, 2006. Adaptado pelos autores.

Cooper et al (2007, p 495) abordam que as justificativas mais comuns da participação do governo no turismo incluem:

1. Ganhos com câmbio de moeda estrangeira e sua importância na balança de pagamentos;

2. Criação de empregos e a necessidade de maximizar os benefícios para a comunidade local; 
3. O fato de que o turismo é uma atividade extensa e fragmentada, que exige uma coordenação cuidadosa do seu desenvolvimento e do marketing;

4. A necessidade de maximizar os benefícios para a comunidade local;

5. A necessidade de distribuir os benefícios e custos de forma equitativa;

6. Construção da imagem do país como um destino turístico;

7. Regulamentação do mercado, de forma a proteger os consumidores e a evitar a concorrência desleal;

8. Oferecimento de infraestrutura e bens públicos, como parte do produto turístico;

9. Necessidade de proteger os recursos e o meio ambiente;

10. A necessidade de normatizar os aspectos do comportamento social, como por exemplo, os jogos de azar;

11. A necessidade de monitorar o impacto da atividade turística através de levantamentos estatísticos.

Cabe salientar a visão de Secchi $(2017$, p. 3) em relação a importância das análises de políticas públicas:

A análise de políticas públicas é a atividade e o campo do conhecimento teórico e metodológico voltados para a geração e a sistematização de conhecimento aplicados ao enfrentamento de problemas públicos. A análise de políticas públicas visa o processo decisório público com o uso de métodos e técnicas de análise de problema (problem analysis) e análise de soluções (solution analysis) para auxiliar nas decisões e na estruturação de políticas, leis, programas, campanhas, projetos e ações públicas (SECCHI, 2017, p. 3).

Devido a este processo de crescimento, o turismo tornou-se uma das atividades mercadológicas com maior índice de desenvolvimento. Houve uma expansão e preocupação com o setor por parte do poder público que passou a fomentar políticas de regulamentação e incentivos à atividade turística. Passou-se a inserir o turismo nas políticas públicas, trabalhando-o de maneira planejada com metas e ações pré-estabelecidas (Silva, Costa \& Carvalho, 2013). 
As relações políticas públicas e turismo se faz necessária, pois quando relacionada às mídias sociais é capaz de melhorar positivamente a reputação da organização turística. Tanto com os clientes quanto com os não clientes, dependendo do alcance. Há possibilidade de ocorrer um impacto consideravelmente alto na atividade e captação de turistas, devido ao fato de transmitir a imagem do destino, segurança e articulação, dentre outros fatores importantes no setor do turismo (Dijkmans, Kerkhof \& Beukeboom, 2015).

Nesse sentido as mídias sociais são essenciais para a divulgação dos destinos e de como o poder público lida com isto, tendo em vista que são uma fonte de informação não apenas dos atrativos turísticos em si, mas de uma gama de questões que estão relacionadas ao setor do turismo (Teles da Mota \& Pickering, 2020).

\section{MIDIAS SOCIAIS E SUA RELAÇÃO COM AS POLÍTICAS PÚBLICAS DE TURISMO}

No que concerne a área do turismo, as tecnologias da informação e comunicação (TICs) nada mais são que um conjunto completo e robusto formado pelas tecnologias eletrônicas, de comunicação e telecomunicação, incluindo todo hardware, software, netware, "necessários para o desenvolvimento e operacionalização da "infraestrutura" do turismo" (Beni, 2017, p. 1).

Desse modo, a tecnologia afetou todos os setores da economia, principalmente o turismo, proporcionando uma grande transformação entre destinos turísticos, organizações, fornecedores e clientes, gerando grandes oportunidades no mundo dos negócios. Esta transição para o mundo digital é um avanço do cenário tecnológico, onde as instituições e empresas podem obter oportunidades para um maior crescimento (Sheng, 2012; Moro, Rita \& Vala, 2016; Choudhary et al., 2020). 
Neste cenário tecnológico as mídias sociais permitem o compartilhamento de informações em formatos de textos, imagens ou vídeos, por meio de grupos ou espaços virtuais (Telles, 2010). Eles possibilitam a publicação de conteúdos por qualquer pessoa e abrangem diversas atividades que integram tecnologia e interação social (Kiralova \& Pavliceka, 2015). Também tem um papel importante pois, a "estimulação comportamental e a criação de atividades comportamentais dos usuários de mídias sociais podem ser usadas para a construção da imagem" (Zucco et al., 2017).

O uso de mídia social do governo tem como ponto forte oferecer oportunidades para que o Estado cumpra com os objetivos básicos de democracia, como por exemplo, ações de transparência, participação cidadã e compromisso, sem demandar um grande investimento para a implementação. Esta intervenção, cabe ao papel social do governo em desvelar os princípios de abertura, responsabilidade, colaboração de todas as partes interessadas e a participação comunitária (Arman \& Sidik, 2019).

Para Li et al., (2019) as mídias sociais são forças significativas na modelagem da orientação e identificação cultural dos usuários e são essenciais na promoção de uma destinação turística. Reforçando esse discurso, Choudhary et al., (2020) enfatizam que a tecnologia da informação aliada a políticas públicas é capaz de promover a paz, pois desempenham um papel vital contra a violência e o terrorismo entre países e economicamente podem aumentar as receitas do turismo substancialmente.

No ramo do turismo a Internet tem sido uma plataforma fundamental para a rápida expansão de serviços de informação, aplicações comerciais, promoção e webmarketing, incluindo sistemas colaborativos, intranet e comércio eletrônico. Suas ferramentas proporcionam também alinhamento com o processo de inovação no turismo (Munar, 2012). Todavia, o processo de promoção do turismo precisa de fomento público alinhado ao setor 
privado para que possa haver desenvolvimento efetivo do setor (Mei, Arcodia \& Ruhanen, 2012).

É importante a atuação do poder público na organização das políticas públicas com a intenção de disseminar a comunicação para promover uma articulação entre os diversos atores sociais envolvidos nos seus planos, programas e projetos (Teles da Mota \& Pickering, 2020).

A importância da promoção aliada a informação é ressaltada por Guerra, Gosling e Coelho (2014, p. 408), os pesquisadores afirmam que "a procura de informação turística é vista como resultado de um processo dinâmico, no qual os viajantes usam vários tipos e quantidades de fontes para responder às contingências internas e externas referentes ao planejamento de viagens", que influenciam a sua tomada de decisão final muitas vezes.

No estudo de Duarte (2009), a comunicação pública ocorre no espaço formado pelos fluxos de informação e de interação entre agentes públicos e atores sociais (governo, estado e sociedade civil - inclusive partidos, empresas terceiro setor e cada cidadão individualmente) em temas de interesse público. Conforme apresentado na figura abaixo.

Figura 1: Fluxos de informação e de interação entre agentes públicos e atores sociais

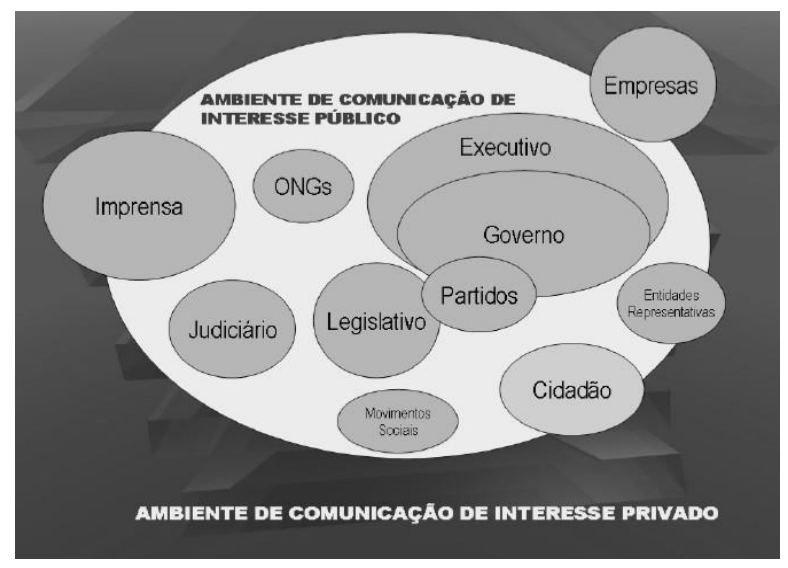

Fonte: Duarte, (2009). 
Ao se tratar de políticas públicas de turismo, primeiramente, é imprescindível reconhecer a importância de tal instrumento para o desenvolvimento de uma determinada região, de modo que a sua implementação exalta o papel do Estado como propulsor do dinamismo neste setor. O processo de descentralização deve ser uma alternativa de aumento da eficiência, otimização e desenvolvimento das potencialidades locais e não como instrumento de fragmentação das diretrizes turísticas do país (Nóbrega, Greci \& Silva, 2016).

Atualmente, os princípios e diretrizes de política de turismo tendem a proporcionar articulação entre os diversos atores sociais envolvidos nos seus planos, programas e projetos, caracterizados pelo processo de descentralização (Knupp \& Mafra, 2012).

Pode-se afirmar que as políticas públicas servem como ações ou instrumentos de gestão, utilizadas para garantir o desenvolvimento de um determinado local, sendo este a cidade, estado ou país voltado para a população, visando acima de tudo à qualidade de vida (Munar, 2012).

Partindo do pressuposto de que a atividade turística engloba vários aspectos operacionais, faz-se necessário um meio de orientar e ordenar a atividade, por meio da elaboração, fiscalização e aplicação de políticas públicas voltadas ao desenvolvimento turístico de um determinado município, onde isso irá acontecer (Coutinho, Thomaz \& Sampaio, 2013).

Nesta perspectiva, e considerando a esfera de marketing no conceito de políticas públicas de turismo, as mídias sociais têm sua devida importância, principalmente no que se refere aos canais sociais de destinos turísticos que integram informação e desenvolvimento (Penteado \& Fortunato, 2015).

Atualmente o conceito de política 2.0 se refere ao esforço que realizam os cidadãos que buscam participar da formulação, desenvolvimento e avaliação das políticas públicas mediante o uso da inteligência coletiva 
presente nas redes sociais que tem se formado para este propósito (Castellanos, Marín \& Montiel, 2011). A política 2.0 permite os cidadãos a se organizarem em rede através das ferramentas disponíveis e exercer influência nas decisões dos políticos e da elaboração e implementação de políticas públicas. A política social perpassa fronteiras geográficas e incrementa a comunicação e interação de grupos sociais envolvidos e interessados em questões políticas (Almeida \& Tavares, 2014).

Um documento importante e que oferece base para este estudo é o "Manual de Orientações para Atuação em Mídias Sociais" (Identidade padrão de comunicação digital do poder executivo federal), disponibilizado pela Secretaria de Comunicação Social Brasileira, em 2014. O objetivo é apresentar aOs agentes da comunidade SECOM (Secretaria de Comunicação Social Brasileira) e instituições públicas integradas à esfera federal quais são as principais diretrizes e caminhos para a utilização assertiva e ética de mídias sociais, considerando a geração de conteúdo, interação com o cidadão e atuação em casos de gerenciamento de crise (Brasil, 2014).

O manual trata de algumas questões especificas sobre a forma como deve ocorrer a comunicação digital no país. Dentre essas, inclui as principais mídias sociais utilizadas no Brasil: Facebook, Youtube, Twitter, Instagram, Flickr, Blogs e Wikipedia. Em resumo, o documento determina passo a passo a devida utilização das mídias citadas, exemplifica funções operacionais e investimentos em publicidade (Brasil, 2014).

O documento apresenta a padronização que os setores do governo devem utilizar em seus canais sociais. A seguir na figura 2 é apresentado o padrão que deve ser utilizado pelas mídias sociais gerenciadas pelo governo: 
Figura 2: Exemplo de integração e padronização dos canais sociais do Portal Brasil TWITTER PORTAL BRASIL
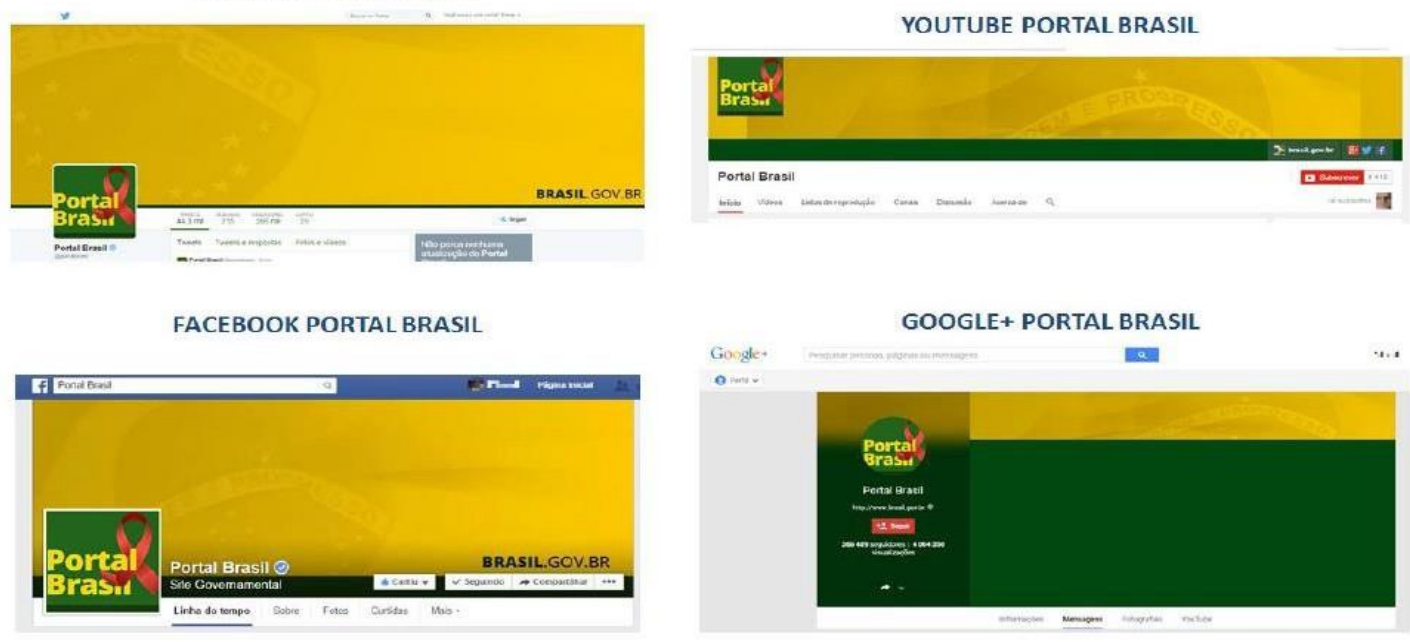

Fonte: Brasil, (2014).

A figura 2 retrata um exemplo utilizando o Portal Brasil, porém o manual contém uma série de sugestões de como os servidores devem lidar com situações cotidianas na web, como crises e resposta a comentários de internautas. Dividido em seis partes - entre elas conceitos básicos, monitoramento de redes sociais e gerenciamento de crises - o manual esclarece, de forma didática, o funcionamento de cada uma das principais mídias sociais, além de recomendar formas de agir em determinadas situações, a partir de casos reais (Brasil, 2014).

\section{PROCEDIMENTOS METODOLOGICOS}

A metodologia utilizada neste estudo foi de caráter qualitativo exploratório com a utilização dos métodos de levantamento bibliográfico, 
análise documental e avaliação de conteúdo na plataforma web. A pesquisa bibliográfica e a pesquisa descritiva são procedimentos técnicos que visam a busca de fontes e informações em materiais já elaborados, conforme ressaltado por Veal (2011). Pode-se considerar como pesquisa avaliativa, pois, segundo o autor, esta surge da necessidade de julgar o sucesso ou a eficácia de políticas ou programas.

A pesquisa se caracteriza como pesquisa documental, que envolve bases de sustentação que contenham " informação registrada, formando uma unidade, que possa servir para consulta, estudo ou prova. Incluem-se nesse universo os impressos, os manuscritos, os registros audiovisuais e sonoros, as imagens, entre outros"(Appolinário, 2009, p. 67). O levantamento bibliográfico foi o método de busca que deu sustentação para o desenvolvimento do referencial teórico e discussões posteriores de resultados, este consistiu na seleção de artigos científicos de periódicos, encontrados na base de dados da EBSCO, Scielo, Web of Science, Publicações em Turismo e Portal Capes. A busca utilizou as seguintes palavras-chaves: políticas públicas de turismo e mídias sociais. Ambas as palavras-chaves em português e inglês no intuito de rastrear os artigos científicos nacionais e internacionais e nos filtros de buscas com as palavras no título, resumo ou palavra-chave.

Nesta etapa, devido a pequena quantidade de artigos, que evidenciassem ambos os termos de busca em um único estudo no campo do turismo, não foi delimitado o período de publicação. Levou-se em consideração as produções científicas mais recentes para desenvolver o contexto teórico.

A análise documental leva em consideração documentos, escritos ou não, como fontes de dados com um conteúdo que serve para identificação, verificação e apreciação de uma análise científica (Costa et al., 2018). Neste estudo foi avaliado o conteúdo do documento "Manual de Orientações para Atuação em Mídias Sociais" (Identidade padrão de 
comunicação digital do poder executivo federal), disponibilizado pela Secretaria de Comunicação Social Brasileira, em 2014. E que serviu posteriormente para avaliar a padronização das mídias sociais do governo brasileiro relacionadas ao turismo em uma análise comparativa dos anos de 2017 e 2020, no período de junho (período de festividades juninas). Foram identificados na análise do Manual de Orientação para atuação em mídias sociais referentes a padronização das mídias socias: Diretrizes gerais, padronizações visuais, conteúdo institucional, conteúdo vivo e noticioso, conteúdo de utilidade pública, produção de conteúdo, gestão de conteúdo, monitoramento e métricas em mídias sociais, engajamento, gestão de relacionamento com o cidadão e gerenciamento de crises de imagem.

Dentre os tópicos, foram escolhidos para o presente estudo apenas os mais relevantes e adequados ao objetivo da pesquisa, sendo estes: padronizações visuais, conteúdo institucional, conteúdo vivo e noticioso e conteúdo de utilidade pública. No quadro (3) a seguir, constam as descrições de cada variável utilizada.

Quadro 3: Descrição das variáveis utilizadas

\begin{tabular}{|l|l|l|}
\hline $\begin{array}{l}\text { Dimensõ } \\
\text { es }\end{array}$ & Variáveis & Descrição \\
\hline \multirow{5}{*}{$\begin{array}{l}\text { Diretriz } \\
\text { Geral }\end{array}$} & $\begin{array}{l}\text { Padronizaçõ } \\
\text { es Visuais }\end{array}$ & $\begin{array}{l}\text { A composição dos elementos visuais deve } \\
\text { representar a proposta ou a essência de um perfil. } \\
\text { Eles têm de representar graficamente a instituição. } \\
\text { cenário ideal é aquele em que ao ver uma peça, } \\
\text { uma imagem com determinados elementos, } \\
\text { usuário identifique rapidamente de quem é aquela } \\
\text { informação e qual a mensagem transmitida por ela. }\end{array}$ \\
\hline \multirow{5}{*}{$\begin{array}{l}\text { Diretrizes } \\
\text { Editoriais }\end{array}$} & $\begin{array}{l}\text { Conteúdo } \\
\text { Institucional }\end{array}$ & $\begin{array}{l}\text { São informações básicas de governo, em geral mais } \\
\text { perenes e atemporais. Elas têm a ver com a } \\
\text { proposta de apresentar, explicar e fixar informações } \\
\text { relevantes para o cidadão. Como exemplo } \\
\text { podemos usar objetivos e metas de programas, } \\
\text { deveres e obrigações do cidadão, entre outros } \\
\text { dados. }\end{array}$ \\
\cline { 2 - 4 } & $\begin{array}{l}\text { Conteúdo } \\
\text { Vivo ou } \\
\text { Noticioso }\end{array}$ & $\begin{array}{l}\text { Trata-se do conteúdo de caráter factual, mas ainda } \\
\text { importante para o dia a dia da população. } \\
\text { Coberturas de eventos e marcos importantes da } \\
\text { economia, dos serviços públicos, das agendas dos }\end{array}$ \\
\hline
\end{tabular}




\begin{tabular}{|l|l|l|}
\hline $\begin{array}{l}\text { Dimensõ } \\
\text { es }\end{array}$ & Variáveis & Descrição \\
\hline \multirow{1}{*}{} & & $\begin{array}{l}\text { ocupantes de cargos públicos e números novos de } \\
\text { pesquisa além de campanhas entram nessa } \\
\text { categoria de informação. }\end{array}$ \\
\cline { 2 - 3 } & $\begin{array}{l}\text { Conteúdo de } \\
\text { Utilidade } \\
\text { Pública }\end{array}$ & $\begin{array}{l}\text { São aquelas informações que o cidadão procura } \\
\text { sobre serviços e processos governamentais. É a } \\
\text { entrega e a atendimento objetivo e direto daquilo } \\
\text { que a população precisa consultar com frequência } \\
\text { ou ainda tem dificuldade em saber como realizar. }\end{array}$ \\
\hline
\end{tabular}

Fonte: Secretaria de Comunicação Social Brasileira, 2014.

A avaliação de conteúdo na plataforma web desenvolveu-se, primeiramente, através da verificação de quais mídias sociais o Ministério do Turismo estava inserido, por meio de links e ícones de divulgação em seu site oficial. A partir deste levantamento, a avaliação consistiu na visitação das páginas ou perfis do Ministério do Turismo nas referidas mídias sociais, e na coleta de informações conforme a sequência indicada no documento: Manual de Orientação para atuação em Mídias Sociais (Identidade padrão de comunicação digital do poder executivo federal)

\section{APRESENTAÇÃO E AVALIAÇÃO DE RESULTADOS}

Diante das variáveis descritas na metodologia foram coletados os dados do período de junho (período de festas juninas) de 2017 e 2020 e conferências das mídias sociais utilizadas pelo Ministério do Turismo. Na qual constam os links em seu site oficial referentes as mídias: Facebook, Twitter, YouTube, Google +, Instagram, Pinterest e Flickr. Estas podem ser verificadas visualmente nas figuras (3) e (4) apresentadas a seguir: 
Figura 3: Mídias sociais utilizadas pelo Ministério do Turismo (Ano de 2017)
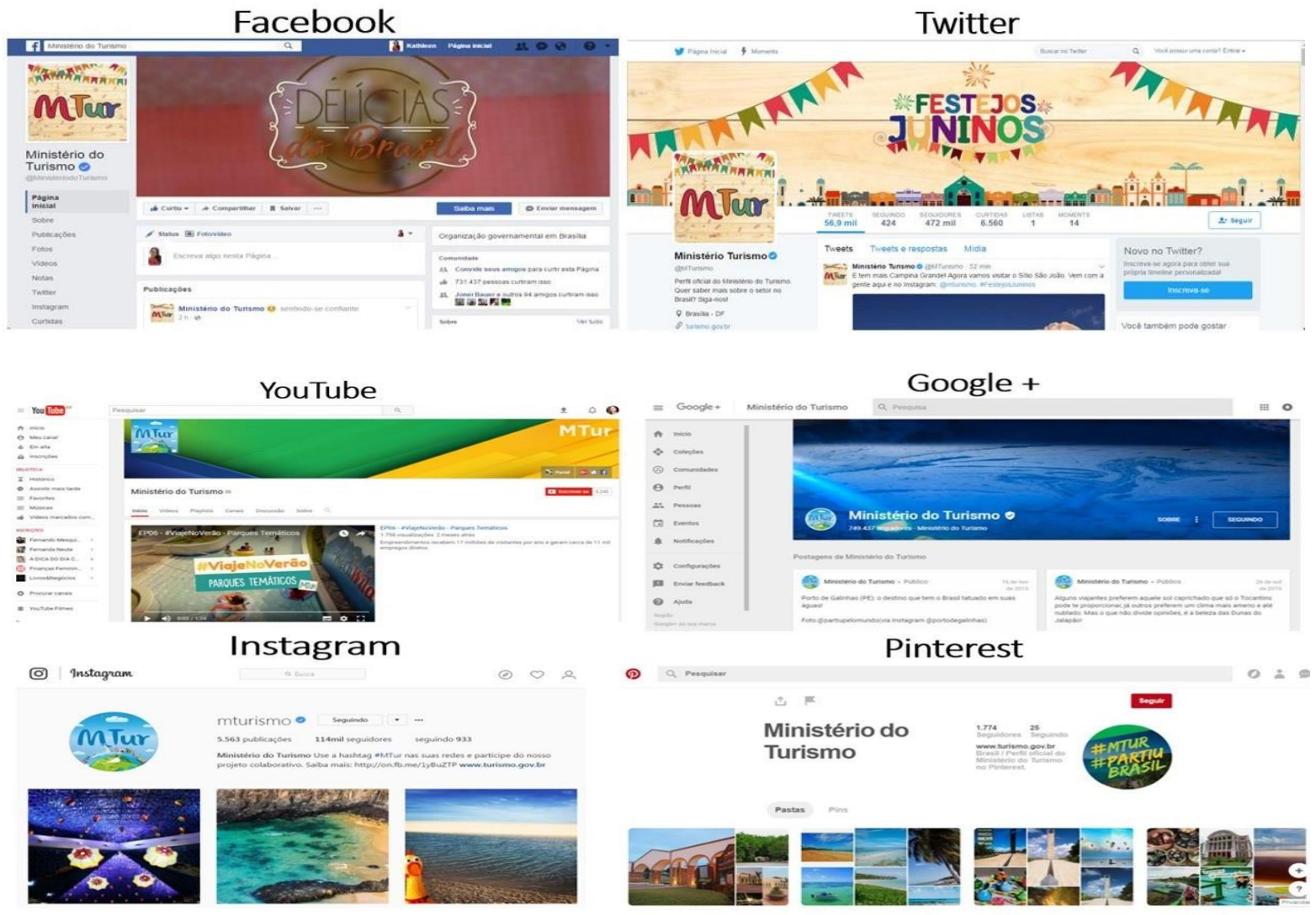

\section{Flickr}

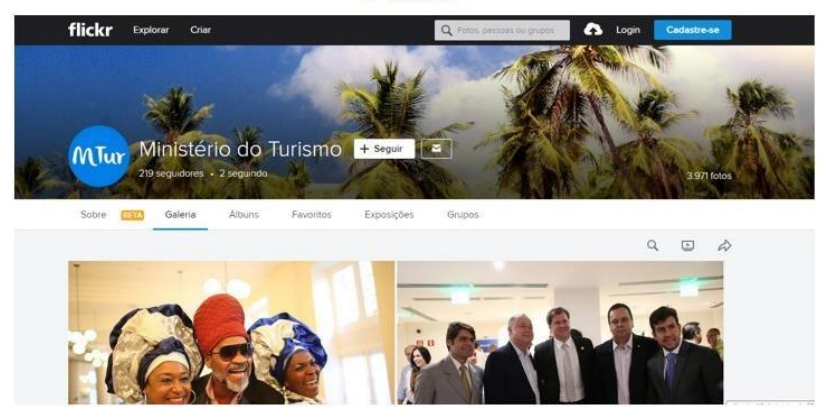

Fonte: Dados coletados pelos autores (2017). 
Figura 4: Mídias sociais utilizadas pelo Ministério do Turismo (Ano de 2020)

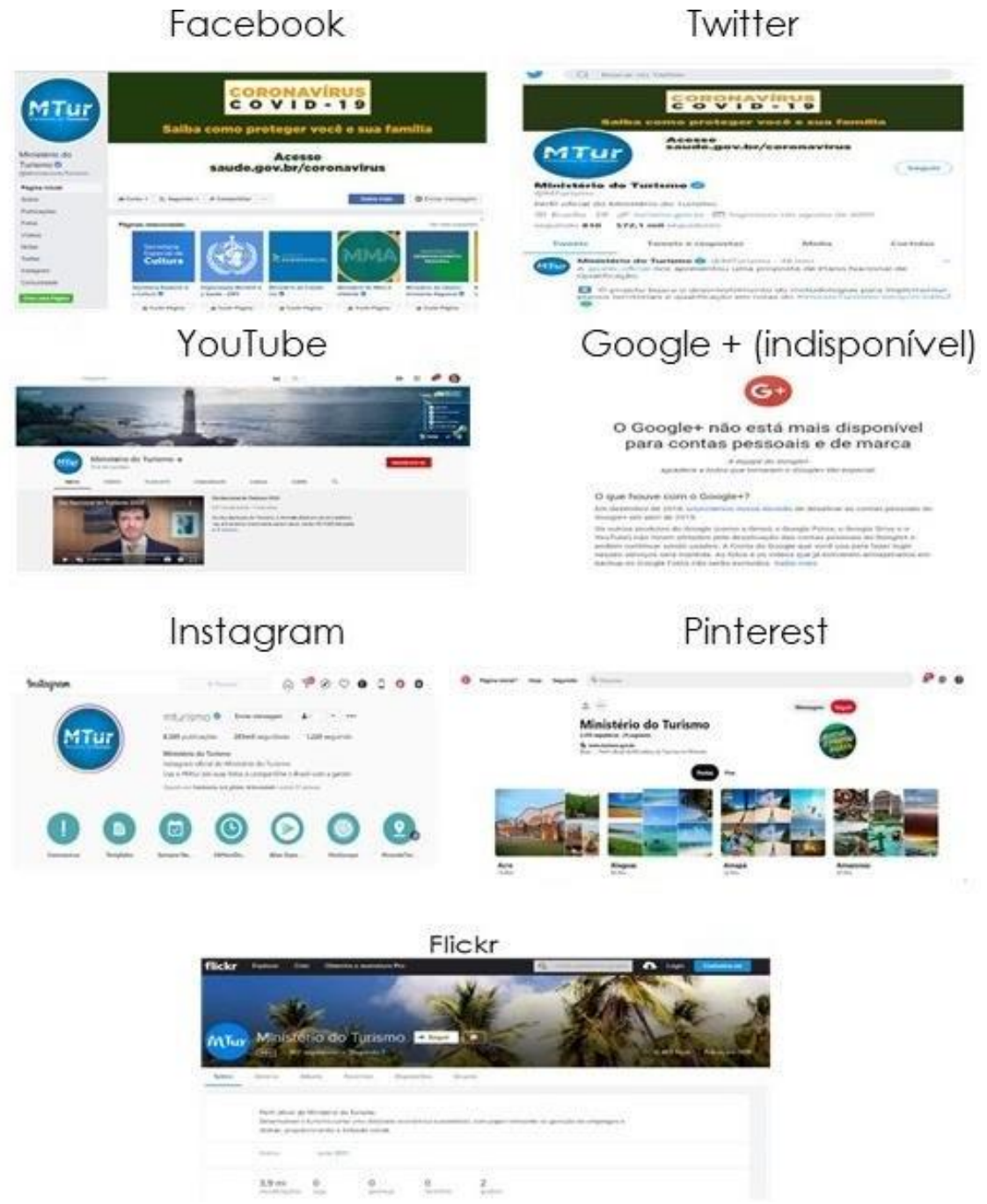

Fonte: Dados coletados pelos autores (2020). 
Para verificar as variáveis mencionadas, apresenta-se abaixo um quadro da avaliação das mídias sociais utilizadas pelo Ministério do Turismo e os principais resultados do estudo, que podem ser vistos nos quadros (4) e (5):

Quadro 4: Avaliação e resultado das variáveis estudadas em cada mídia social (2017)

\begin{tabular}{|c|c|}
\hline Mídia Social & Avaliação \\
\hline $\begin{array}{l}\text { Facebook } \\
\text { (fanpage) }\end{array}$ & $\begin{array}{l}\text { Padronização Visual: Apresenta a imagem do perfil referente a } \\
\text { campanha temática de "Festejos Juninos", e plano de fundo } \\
\text { com vídeo. } \\
\text { Conteúdo Institucional: Apresenta materiais de consulta, } \\
\text { pesquisas realizadas e divulga os destinos do Brasil. } \\
\text { Conteúdo Vivo e Noticioso: Contempla notícias sobre o setor, } \\
\text { agenda, coberturas de eventos em destinos. } \\
\text { Conteúdo de Utilidade Pública: Apresenta descrição do } \\
\text { Ministério, a missão, endereço, telefone de contato e link do site } \\
\text { oficial, divulga dicas de viagem (no sentido operacional, } \\
\text { regulamentos, entre outros). }\end{array}$ \\
\hline $\begin{array}{l}\text { Twitter } \\
473 \text { mil } \\
\text { seguidores }\end{array}$ & $\begin{array}{l}\text { Padronização Visual: Apresenta imagem do perfil e plano de } \\
\text { fundo referente a campanha temática de "Festejos Juninos". } \\
\text { Conteúdo Institucional: Pela função da mídia social, os tweets } \\
\text { abordam algo relacionado a hashtag utilizada no momento, } \\
\text { sendo a atual \#Festejos Juninos. } \\
\text { Conteúdo Vivo e Noticioso: Apresenta notícias de destinos. } \\
\text { Conteúdo de Utilidade Pública: Dispõe esporadicamente sobre } \\
\text { dicas de viagem (novos regulamentos, características do } \\
\text { destino, entre outros). }\end{array}$ \\
\hline
\end{tabular}




\begin{tabular}{|c|c|}
\hline Mídia Social & Avaliação \\
\hline $\begin{array}{l}\text { YouTube } \\
5.249 \text { mil } \\
\text { inscritos }\end{array}$ & $\begin{array}{l}\text { Padronização Visual: Apresenta a imagem do perfil referente a } \\
\text { atual marca visual do Ministério do Turismo. } \\
\text { Conteúdo Institucional: Apresenta vídeos de comercialização } \\
\text { de destinos do Brasil. } \\
\text { Conteúdo Vivo e Noticioso: Apresenta vídeos com notícias de } \\
\text { destinos, coberturas de eventos. } \\
\text { Conteúdo de Utilidade Pública: Não consta. }\end{array}$ \\
\hline $\begin{array}{l}\text { Google + } \\
749.910 \text { mil } \\
\text { seguidores }\end{array}$ & $\begin{array}{l}\text { Padronização Visual: Apresenta a imagem do perfil referente a } \\
\text { atual marca visual do Ministério do Turismo, a imagem de plano } \\
\text { de fundo encontra-se destacada como "Chapada } \\
\text { Diamantina". } \\
\text { Conteúdo Institucional: Apresenta imagens de comercialização } \\
\text { de destinos do Brasil, com base em fotos postadas por turistas ou } \\
\text { seguidores. Contém a última postagem da página no dia } 16 \text { de } \\
\text { novembro de } 2015 \text {, } \\
\text { Conteúdo Vivo e Noticioso: Não consta. } \\
\text { Conteúdo de Utilidade Pública: Não consta. }\end{array}$ \\
\hline $\begin{array}{l}\text { Instagram } \\
114 \text { mil } \\
\text { seguidores }\end{array}$ & $\begin{array}{l}\text { Padronização Visual: Apresenta a imagem do perfil referente a } \\
\text { atual marca visual do Ministério do Turismo } \\
\text { Conteúdo Institucional: Apresenta imagens de comercialização } \\
\text { de destinos do Brasil, com base em fotos postadas por turistas ou } \\
\text { seguidores. } \\
\text { Conteúdo Vivo e Noticioso: Apresenta imagens e vídeos de } \\
\text { coberturas de eventos nos destinos. } \\
\text { Conteúdo de Utilidade Pública: Não consta. }\end{array}$ \\
\hline $\begin{array}{l}\text { Pinterest } \\
1.774 \\
\text { seguidores }\end{array}$ & $\begin{array}{l}\text { Padronização Visual: Apresenta a imagem do perfil destacada } \\
\text { pela campanha (\#Mtur \#PartiuBrasil) } \\
\text { Conteúdo Institucional: Possui pastas de cada destino do Brasil, } \\
\text { e apresenta imagens relacionadas ao destino (atrativos, } \\
\text { eventos, cultura, clima, entre outros). } \\
\text { Conteúdo Vivo e Noticioso: Não consta. } \\
\text { Conteúdo de Utilidade Pública: Não consta. }\end{array}$ \\
\hline
\end{tabular}




\begin{tabular}{|c|c|}
\hline Mídia Social & Avaliação \\
\hline $\begin{array}{l}\text { Flickr } \\
219 \text { seguidores }\end{array}$ & $\begin{array}{l}\text { Padronização Visual: Apresenta a imagem do perfil referente a } \\
\text { atual marca visual do Ministério do Turismo. } \\
\text { Conteúdo Institucional: Apresenta galerias com imagens. O } \\
\text { principal objetivo são coberturas realizadas pelo Ministro do } \\
\text { Turismo e representantes do setor. } \\
\text { Conteúdo Vivo e Noticioso: Apresenta galerias com imagens, } \\
\text { descrição e datas de cerimônias, palestras, fóruns, aberturas, } \\
\text { seminários, espetáculos, debates e reuniões de setor, etc. } \\
\text { Conteúdo de Utilidade Pública: Não consta. }\end{array}$ \\
\hline
\end{tabular}

Fonte: Elaborado pelos autores com base nos dados coletados em junho, 2017.

O quadro (4) apresenta os resultados de 2017, mostra que alguns pontos referendados pela Secretaria de Comunicação Social Brasileira (2014) são contemplados e outros não. Percebe-se que o foco do calendário de eventos de junho de 2017 era transmitir para o público-alvo o conteúdo idealizado pelos profissionais que trabalham com as mídias sociais do governo, focando em fatores socioculturais, que são importantes e precisam estar presentes nas ações governamentais no setor do turismo centradas no turista e nos residentes (Gastal \& Moesch, 2007; Ferguson \& Bornstein, 2012).

○ quadro (5)a seguir, mostra avaliação das mídias em um momento de crise de saúde, que causa desestabilização do setor em nível mundial.

Quadro 5: Avaliação e resultado das variáveis estudadas em cada mídia social (2020)

\begin{tabular}{|c|c|}
\hline Mídia Social & Avaliação \\
\hline $\begin{array}{l}\text { Facebook } \\
\text { (fanpage) }\end{array}$ & $\begin{array}{l}\text { Padronização Visual: Apresenta a imagem do perfil referente a } \\
\text { campanha COVID-19. } \\
\text { Conteúdo Institucional: Apresenta materiais de consulta, } \\
\text { pesquisas realizadas e divulga os destinos do Brasil. } \\
\text { Conteúdo Vivo e Noticioso: Contempla notícias sobre o setor, } \\
\text { agenda, coberturas de eventos em destinos, ligados ao } \\
\text { momento pandêmico. } \\
\text { Conteúdo de Utilidade Pública: Apresenta descrição do } \\
\text { Ministério, a missão, endereço, telefone de contato e link do site }\end{array}$ \\
\hline
\end{tabular}




\begin{tabular}{|c|c|}
\hline Mídia Social & Avaliação \\
\hline & $\begin{array}{l}\text { oficial, divulga dicas de viagem (no sentido operacional, } \\
\text { regulamentos, entre outros). }\end{array}$ \\
\hline $\begin{array}{l}\text { Twitter } \\
572,1 \text { mil } \\
\text { seguidores }\end{array}$ & $\begin{array}{l}\text { Padronização Visual: Apresenta a imagem do perfil referente a } \\
\text { campanha COVID-19. } \\
\text { Conteúdo Institucional: Pela função da mídia social, os tweets } \\
\text { abordam algo relacionado a hashtag utilizada no momento, } \\
\text { sendo a atual \#ObrasMTur e \#PlanoDeRetomadaDoTurismo } \\
\text { Conteúdo Vivo e Noticioso: Apresenta notícias de destinos, } \\
\text { planos e atualizações referente ao COVID-19. } \\
\text { Conteúdo de Utilidade Pública: Dispõe esporadicamente sobre } \\
\text { dicas de viagem (novos regulamentos relacionados a saúde, } \\
\text { características do destino, entre outros). }\end{array}$ \\
\hline $\begin{array}{l}\text { YouTube } \\
11,6 \text { mil inscritos }\end{array}$ & $\begin{array}{l}\text { Padronização Visual: Apresenta a imagem do perfil referente a } \\
\text { Praia de Itapuã - Salvador (BA). } \\
\text { Conteúdo Institucional: Apresenta vídeos de comercialização } \\
\text { de destinos do Brasil e, vídeo institucional referente ao dia } \\
\text { nacional do turismo, além de vídeos motivando destinos na } \\
\text { época de pandemia. } \\
\text { Conteúdo Vivo e Noticioso: Apresenta vídeos com notícias de } \\
\text { destinos, coberturas de eventos. } \\
\text { Conteúdo de Utilidade Pública: Não consta. }\end{array}$ \\
\hline Google + & $\begin{array}{l}\text { Perfil não encontrado devido a desativação de contas e } \\
\text { marcas pela própria plataforma, Google+ em abril de } 2019 \text {. }\end{array}$ \\
\hline $\begin{array}{l}\text { Instagram } \\
283 \text { mil } \\
\text { seguidores }\end{array}$ & $\begin{array}{l}\text { Padronização Visual: Apresenta a imagem do perfil referente a } \\
\text { atual marca visual do Ministério do Turismo. } \\
\text { Conteúdo Institucional: Apresenta imagens de comercialização } \\
\text { de destinos do Brasil, com base em fotos postadas por turistas ou } \\
\text { seguidores. } \\
\text { Conteúdo Vivo e Noticioso: Apresenta imagens e vídeos de } \\
\text { coberturas sobre os planos de Medidas Provisórias no combate } \\
\text { a CoVID-19. } \\
\text { conteúdo de Utilidade Pública: Apresenta protocolos de } \\
\text { segurança e higiene que servem tanto para o turista quanto } \\
\text { para o setor. }\end{array}$ \\
\hline
\end{tabular}




\begin{tabular}{|c|c|}
\hline Mídia Social & Avaliação \\
\hline $\begin{array}{l}\text { Pinterest } \\
2.285 \\
\text { seguidores }\end{array}$ & $\begin{array}{l}\text { Padronizacão Visual: Apresenta a imagem do perfil destacada } \\
\text { pela campanha (\#Mtur \#PartiuBrasil) } \\
\text { Conteúdo Institucional: Possui pastas de cada destino do Brasil, } \\
\text { e apresenta imagens relacionadas ao destino (atrativos, } \\
\text { eventos, cultura, clima, entre outros). } \\
\text { Conteúdo Vivo e Noticioso: Não consta. } \\
\text { Conteúdo de Utilidade Pública: Não consta. }\end{array}$ \\
\hline $\begin{array}{l}\text { Flickr } \\
362 \text { seguidores }\end{array}$ & $\begin{array}{l}\text { Padronização Visual: Apresenta a imagem do perfil referente a } \\
\text { atual marca visual do Ministério do Turismo. } \\
\text { Conteúdo Institucional: Apresenta galerias com imagens. O } \\
\text { principal objetivo são coberturas realizadas pelo Ministro do } \\
\text { Turismo e representantes do setor. } \\
\text { Conteúdo Vivo e Noticioso: Apresenta galerias com imagens, } \\
\text { descrição e datas de cerimônias, palestras, fóruns, aberturas, } \\
\text { seminários, espetáculos, debates e reuniões de setor, etc. } \\
\text { Conteúdo de Utilidade Pública: Não consta. }\end{array}$ \\
\hline
\end{tabular}

Fonte: Elaborado pelos autores com base nos dados coletados em Junho (2020).

Os resultados de 2020 assim como os de 2017, atendem parcialmente os critérios da Secretaria de Comunicação Social Brasileira (2014), já que ambos conseguem transmitir a partir da padronização uma mensagem direta e clara dentro do contexto da comunicação nas mídias sociais. Os dados analisados dos anos de 2017 e 2020, revelam um crescimento considerável no número de seguidores/curtidas nas páginas oficiais do ministério. Percebe-se o engajamento das páginas oficiais do Ministério, como Facebook, Youtube e Instagram.

No ano de 2020 as mídias sociais do governo ligadas ao turismo tentam motivar o pequeno e médio empreendedor, com políticas publicadas visivelmente ligadas a gestão de crise desencadeada pela pandemia COVID-19. Ações como essas já foram destacadas como importantes por Dijkmans, Kerkhof e Beukeboom (2015). A preocupação com a saúde pública é evidente, verifica-se que campanhas são feitas orientando turistas, residentes e empresas do setor por meio de imagens, vídeos e manuais 
presentes nas mídias sociais, com as formas de prevenção relacionadas ao COVID-19. Essas ações desenvolvida através de conteúdos como fotos, documentos e vídeos, podem impactar na projeção da imagem de destino como já apontado por Zucco et al., (2018) e aquecimento do setor posteriormente, e mostram também a importância do papel do governo para o desenvolvimento sustentável do turismo já destacado por Mei, Arcodia e Ruhanen (2012) no resultado de suas pesquisas.

Identificou-se um crescimento considerável no número de seguidores das mídias do governo comparando 2017 a 2020, o que pode estar relacionado a crescimento do uso das redes sociais no período de pandemia do COVID-19 já identificado por (De Castro, 2020).

Os achados de pesquisa mostram que existe uma preocupação com a satisfação do visitante, a proteção do meio ambiente através de algumas ações relacionas a sustentabilidade, e estímulo para crescimento do turismo mesmo em tempos de crise, já pontuados por Beni (2006), e que fazem parte das políticas públicas de turismo.

Apesar de não serem encontrados estudos que contemplem outras perspectivas de união das temáticas abordadas aqui, há que se ponderar que Almeida e Tavares (2014), já consideravam que uma sociedade com acesso aos meios de comunicação estruturados na internet e ativa com a população através de suas ferramentas, tendem a alavancar a um crescimento democrático no país, proporcionado pelo cenário online.

A abordagem de vários pontos de vista e aspectos da sociedade civil, incluindo a atividade turística, desenvolve o fortalecimento de uma democracia que faz uso devido dos distintos elementos tecnológico e de informações relevantes, por parte de representantes e representados

\section{CONSIDERAÇÕES FINAIS}

Através da análise bibliográfica, constatou-se que atualmente as mídias sociais estão estrategicamente sendo utilizadas em diversas áreas, além de 
contribuir de forma relacional com as políticas e questões públicas do país. Verificou-se a relação importante que mídias sociais podem exercer na consolidação das políticas públicas que servem como ações ou instrumentos de gestão, utilizadas para garantir o desenvolvimento de um determinado local, sendo este a cidade, estado ou país voltado para a população.

Com relação aos resultados obtidos, percebeu-se uma inadequação da padronização visual utilizada entre todas as mídias sociais do Ministério do Turismo no ano de 2017. Na atualização dos dados percebe-se que no ano de 2020 algumas mídias sociais ainda seguem sem um padrão geral, ou seja, fica evidente que não há uma comunicação visual (banners, criativos, mudança na marca, etc) que se atualize entre todas as páginas oficiais. No que se refere as tipologias de material postado, estes justificam-se a adequação de postagens alinhados a proposta de cada mídia social, porém, de uma maneira bem aproximada do que propõe o manual, em todas as mídias verificadas constam publicações de conteúdo institucional.

Considera-se um crescimento atrativo nas quantidades de números de seguidores ou curtidas, das páginas oficiais do ministério conforme a análise de 2017 a 2020. Pontua-se que mediante o fato da pandemia do COVID-19, a partir do mês de março de 2020, observou-se um aumento de interações na rede social "Instagram", resultado do momento circunstancial ao qual despertou preocupação perante as novas medidas a serem adotadas para a manutenção do setor turístico.

Através do documento norteador do estudo: "Manual de Orientações para Atuação em Mídias Sociais" (Identidade padrão de comunicação digital do poder executivo federal), constatou-se que as principais regras, orientações e consolidação das práticas virtuais utilizadas, incluindo a geração de conteúdo, interação com o usuário e atuação em casos de crise, foram identificadas nas mídias sociais oficiais do Ministério do Turismo.

Além disto, a elaboração do presente estudo teve algumas limitações visto a carência de pesquisas envolvendo o uso das redes sociais por 
políticas públicas e o fato de cada mídia social apresentar funções divergentes e não constar publicação de "conteúdo vivo ou noticioso" e "conteúdo de utilidade pública", dificultando a avaliação das variáveis contidas na literatura. No entanto, destaca-se que, através da interatividade e dinamismo na relação e comunicação entre o poder público e a sociedade, possibilitam o surgimento e a consolidação de uma democracia mais modernizada, perante a comunicação e o setor de turismo.

Para a realização de futuras pesquisas, recomenda-se expandir a discussão sobre o tema, e considera-se válido um próximo estudo que avalie as demais variáveis apresentadas pelo manual de orientações: gestão de conteúdo, monitoramento e métricas em mídias sociais, engajamento, gestão de relacionamento com o cidadão e gerenciamento de crises de imagem, no intuito de expandir os estudos do turismo nesta temática. Sugere-se também que os estudos sejam longitudinais a fim de oferecer uma maior contribuição gerencial para o desenvolvimento de políticas públicas interligadas as mídias sociais.

\section{REFERÊNCIAS}

Almeida, G. C., \& Tavares, W. (2014). Redes Sociais Virtuais e a Democracia 2.0: Dinâmicas e Perspectivas Políticas na Relação entre Políticos e Sociedade. RP3-Revista de Pesquisa em Políticas Públicas, 1 (1).

Appolinário, F. (2009). Dicionário de metodologia científica: um guia para a produção do conhecimento científico. São Paulo: Atlas.

Arman, A. A., \& Sidik, A. P. (2019). Measurement of Engagement Rate in Instagram (Case Study: Instagram Indonesian Government Ministry and Institutions). Proceeding - 2019 International Conference on ICT for Smart Society: Innovation and Transformation Toward Smart Region, ICISS 2019. https://doi.org/10.1 109/ICISS48059.2019.8969826.

Beni, M. C. (2006). Analise Estrutural do Turismo. 11. Ed. São Paulo: Senac.

Beni, M. C. (2017). Entendendo o Novo Turismo na Economia Colaborativa e Compartilhada. Associação de Pós Graduação em Turismo - Anptur.

Castellanos, R. M., Marín, M. O., \& Montiel, L. H. (2011). Tecnologías de la comunicación y política 2.0. Espacios públicos, 14 (30), 72-84.

De Castro, F. F. (2020). Impactos da Covid-19 sobre os processos comunicacionais: Primeiras observações sobre dinâmicas, impasses e riscos. Papers do NAEA, 29(1). 
Costa, W. F., Tito, A. L. A., Brumatti, P. N. M., \& Alexandre, M. L. O. (2018). Uso de Instrumentos de Coleta de Dados em Pesquisa Qualitativa: Um Estudo em Produções Científicas de Turismo. Turismo: Visão e Ação, 20(1), 2-28.

Choudhary, S. A., Khan, M. A., Sheikh, A. Z., Jabor, M. K., Nordin, M. S. bin, Nassani, A. A., Alotaibi, S. M., Abro, M. M. Q., Vo, X. V., \& Zaman, K. (2020). Role of information and communication technologies on the war against terrorism and on the development of tourism: Evidence from a panel of 28 countries. Technology in Society, 62, 101296.

Clemente, A. C. F. \& Stoppa, E. A. (2018). Políticas Públicas de Turismo e Lazer do órgão oficial de turismo na Cidade de São Paulo-SP. Revista Rosa dos Ventos Turismo e Hospitalidade, 10(2), pp. 355-369.

Cooper, C. et al. (2007). Turismo Princípios e Práticas. 3. Ed. São Paulo: Bookman.

Coutinho, O. G. P., Thomaz, G. M., \& Sampaio, C. A. (2013). Turismo comunitário e internet: análise dos sites das experiências no Brasil. Caderno Virtual de Turismo, 15(1), p. 35-51.

Dijkmans, C., Kerkhof, P., \& Beukeboom, C. J. (2015). A stage to engage: Social media use and corporate reputation. Tourism Management, 47, 58-67. https://doi.org/https://doi.org/10.1016/j.tourman.2014.09.005

Duarte, J. (2009). Comunicação pública: estado, mercado, sociedade e interesse público. São Paulo: Atlas.

Ferguson, G. M., \& Bornstein, M. H. (2012). Remote acculturation: The "Americanization" of Jamaican islanders. International Journal of Behavioral Development, 36(3), 167-177.

Gastal, S \& Moesch, M. (2007). Turismo, Políticas Públicas e Cidadania. São Paulo: Aleph.

Guerra, A. C., Gosling, M., \& Coelho, M. F. (2014). Redes Sociais: um jornal on-line como fonte de informação especializada em turismo. Revista Brasileira de Pesquisa em Turismo. São Paulo, 8(3),403-418.

Kiralova, A., \& Pavliceka (2015). A. Development of social media strategies in tourism destination. Procedia-Social and Behavioral Sciences, 175, 358-366.

Knupp, M. E., \& Mafra, F. L. (2012). Redes do Turismo: uma análise da política de turismo do Estado de Minas Gerais - Brasil. Turismo em Análise, 23(3), 663-690.

Li, C., Guo, S., Wang, C., \& Zhang, J. (2019). Veni, vidi, vici: The impact of social media on virtual acculturation in tourism context. Technological Forecasting and Social Change, 145, 513-522. https://doi.org/https://doi.org/10.1016/j.techfore.2019.01.013

Mei, X. Y., Arcodia, C., \& Ruhanen, L. (2012). Towards tourism innovation: A critical review of public polices at the national level. Tourism Management Perspectives, 4, 92 105.https://doi.org/https://doi.org/10.1016/j.tmp.2012.05.002 Minazzi, R. (2015). Social media marketing in tourism and hospitality. Cham: Springer.

Moro, S., Rita, P., \& Vala, B. (2016). Predicting social media performance metrics and evaluation of the impact on brand building: A data mining approach. Journal of Business Research, 69(9), 3341-3351.

Munar, A. M. (2012). Social media strategies and destination management. Scandinavian Journal of Hospitality and Tourism, 12(2), 101-120.

Nóbrega, R. F., Grechi, D. C., \& Silva, L. F. (2016). Indicadores na análise das políticas públicas de turismo e da cooperação regional: Um estudo de Ponta Porã e Dourados. Mato Grosso do SUl. TURyDES - Revista Turismo y Desarrollo Local, 9. 
Penteado, C. C., \& Fortunato, I. (2015). Mídia e Políticas Públicas: Possíveis Campos Exploratórios. Revista Brasileira de Ciências Sociais, v. 30, n. 87.

Secchi, L. (2017). Analise de politicas públicas: Diagnótico de problemas e recomendação de soluções. São Paulo- SP: Cengage Learning.

SECOM. Secretaria de Comunicação Social Brasileira. (2014). Manual de orientação para atuação em mídias sociais. Brasília: Poder Executivo Federal.

Sheng, M. L. (2012). The utilitarian and social dual presence in Web 2.0 services. Total Quality Management \& Business Excellence, 23(1), p. 875-890.

Sheppard, V. A., \& Fennell, D. A. (2019). Progress in tourism public sector policy: Toward an ethic for non-human animals. Tourism Management, 73, 134-142. https://doi.org/https://doi.org/10.1016/j.tourman.2018.11.017.

Silva, F. S., Costa, S. R \& Carvalho, C. M. B. (2013). Políticas Públicas de Turismo No Brasil: estratégias para administração da atividade no país. X SEGET, Simpósio de Excelência de Gestão e Tecnologia para competitividade.

Souza, S., \& Machado, D. (2017). Uso e Influência das Mídias Sociais no Planejamento de Viagens: um estudo quantitativo. Revista Turismo Em Análise, 28(2), 254-270. https://doi.org/10.11606/issn.1984-4867.v28i2p254-270

Teles da Mota, V., \& Pickering, C. (2020). Using social media to assess nature-based tourism: Current research and future trends. Journal of Outdoor Recreation and Tourism, 30, 100295. https://doi.org/https://doi.org/10.1016/j.jort.2020.100295.

Telles, A. (2010). A revolução das Mídias Sociais: Estratégias de Marketing digital para você e sua empresa terem sucesso nas Mídias sociais. São Paulo: Makron Books.

Thomaz, G. M., Biz, A. A., Bettoni, E. M., \& Filho, L. M. (2016). Mineração de Conteúdo em Mídias Sociais: análise de conteúdos publicados por usuários sobre atrativos turísticos de Curitiba-PR. Marketing \& Tourism Review, 1(2). https://doi.org/10.29149/mtr.v1i2.3846.

Veal, J. (2011). Metogologia de Pesquisa em Lazer e Turismo. São Paulo: Aleph.

Vignati, F. (2008). Gestão de destinos turísticos: como atrair pessoas para pólos, cidades e países. São Paulo: Senac.

Zucco, F. D., de Lima Pereira, M., Limberger, P. F., \& Falaster, C. D. (2018). Avaliação da imagem de um destino turístico no Instagram. Turismo-Visão e Ação, 20(3), 490. 